\title{
Challenges of Achieving an Optimum Glycemic Control in Children with Type 1 Diabetes in India
}

\author{
Anju Seth ${ }^{1}$ (D) \\ Received: 30 April 2020 / Accepted: 4 May 2020 / Published online: 14 May 2020 \\ (C) Dr. K C Chaudhuri Foundation 2020
}

Achieving and sustaining a good glycemic control while a child with type 1 diabetes (T1DM) integrates diabetes care in his daily life routine, is a big challenge. As the child with diabetes grows, he undergoes a variety of physical, psychological and life style changes. Changes in his own understanding of the disease, increasing self-reliance in diabetes management as parents gradually relinquish their control, academic compulsions, peer pressure for leading a certain lifestyle, all tend to influence the glycemic control.

Achieving an optimum glycemic control in these children requires, to say the least, a customised insulin regime that is dynamic and responsive to the child's daily schedules, selfmonitoring of blood glucose and ability to use the results to adjust the insulin dose, following a regulated meal pattern, skills to manage different types of insulins and their administration, regular exercise, and knowledge about management of sick days and hypoglycemia. Critical in imparting these skills and knowledge is regular engagement with a multidisciplinary healthcare team with expertise in managing childhood diabetes. This team treats, trains, motivates and supports the child and the family while they negotiate various challenges they face. Imparting a sound knowledge about various aspects of the disease to the child and the family is one of the important roles the healthcare team plays.

In resource limited circumstances the challenges to achieve a good control become multi-fold. Financial constraints, limited availability of free insulin and delivery devices and almost negligible availability of free blood glucose monitoring strips, maintaining a consistent carbohydrate intake and adjusting insulin dose in a population that conventionally consumes a carbohydrate rich diet and a significant proportion of which is

Anju Seth

anjuseth.peds@gmail.com

1 Division of Pediatric Endocrinology, Department of Pediatrics, Lady Hardinge Medical College, Kalawati Saran Children's Hospital, Bangla Sahib Marg, New Delhi 110001, India uneducated, are some of the challenges for diabetes management in India. Newer techniques like Continuous Glucose Monitoring and insulin pump are beyond the reach of most patients. Moreover, there is limited availability of expertise to manage this complex disease and hence the need for patients to travel long distances to seek guidance, which is usually not feasible at regular intervals.

In such a situation, the simple and lucid message given in the study by Mangala et al. from SGPGI Lucknow, a Centre offering quality care to children with T1DM offers a ray of hope [1]. The authors have shown that the single most important factor that determined the glycemic control in their cohort of children with TIDM ( $n=173$, age 3-26 y) was their score on diabetes knowledge test, a tool developed and validated by their Centre to assess diabetes knowledge among children and their caregivers [2]. There was no influence of gender, type of residence, insulin regime or per-capita income on the HbA1C levels. Low income has previously been reported to be linked to glycemic control [3-5]. Importantly, the control was not worse among the adolescents, another finding reported earlier $[6,7]$.

Diabetes knowledge is one of the few modifiable factors among many constraints that are a challenge to achieving a good glycemic control. Training and utilizing the services of the available personnel in a health -care setting like nutritionists and nursing officers to function as diabetes educators goes a long way in achieving this goal. Development of a structured diabetes education program and its stepwise delivery to the children with T1DM and their caregivers is feasible and is being successfully carried out at many Centres $[8,9]$. This can be initiated at the time of diabetes diagnosis concurrent with management of diabetes related morbidities and insulin dose titration. This should be followed by periodic reinforcement guided by the need of the child when they come for follow up visits. Conducting periodic workshops for children/caregivers enhances their knowledge and skills apart from giving an opportunity to address their queries. It is desirable to develop patient education booklets in local language 
which the family can refer to when required. Indian Society of Paediatric and Adolescent Endocrinology has several patient education materials available free of cost on its website which can be shared with the patients by the healthcare professionals [10]. Empowering the child and his family to take the reins of diabetes management in their hands is the single most important intervention to improve glycemic control and quality of life.

Other sobering findings from this study were poor awareness in the society about childhood diabetes, reflected by poor injection practice in school/college, and a 35\% prevalence of overweight/obesity among the study subjects. Combination of diabetes and obesity confers a high risk of cardio-vascular morbidity in this vulnerable group. India has the dubious distinction of being the country with the highest prevalence as well as incidence of type 1 diabetes among children upto $14 \mathrm{y}$ of age in the world [11]. Thus, there is an urgent need for active advocacy by the pediatricians and for creating facilities for these children at school/work place and for inclusion of mandatory sports in school curriculum to encourage a heathy lifestyle by the policy makers.

\section{Compliance with Ethical Standards}

Conflict of Interest None.

\section{References}

1. Mangla P, Gupta S, Chopra A, Bhatia V, Vishwakarma R, Asthana P. Influence of socio-economic and cultural factors on type 1 diabetes management: report from a tertiary care multidisciplinary diabetes management center in India. Indian J Pediatr. 2020. https:// doi.org/10.1007/s12098-020-03227-w.
2. Mangla P, Chopra A, Sudhanshu S, et al. Validation of a diabetes knowledge test for Indian children, adolescents and young adults with type 1 diabetes mellitus. Prim Care Diabetes. 2019;13:283-7.

3. Deladoëy J, Henderson M, Geoffroy L. Linear association between household income and metabolic control in children with insulindependent diabetes mellitus despite free access to health care. J Clin Endocrinol Metab. 2013;98:E882-5.

4. Gomes MB, de Mattos Matheus AS, Calliari LE, et al. Economic status and clinical care in young type 1 diabetes patients: a nationwide multicenter study in Brazil. Acta Diabetol. 2013;50:743-52.

5. Hatherly K, Smith L, Overland J, et al. Glycemic control and type 1 diabetes: the differential impact of model of care and income. Pediatr Diabetes. 2011;12:115-9.

6. Phelan H, Clapin H, Bruns L, et al. The Australasian diabetes data network: first national audit of children and adolescents with type 1 diabetes. Med J Aust. 2017;206:121-5.

7. Miller KM, Foster NC, Beck RW, et al; T1D Exchange Clinic Network. Current state of type 1 diabetes treatment in the U.S.: updated data from the T1D Exchange clinic registry. Diabetes Care. 2015;38:971-8.

8. Xie Y, Liu F, Huang F, et al. Establishment of a type 1 diabetes structured education programme suitable for Chinese patients: type 1 diabetes education in lifestyle and self adjustment (TELSA). BMC Endocr Disord. 2020;20:37.

9. Campbell F, Lawton J, Rankin D, et al. Follow-up support for effective type 1 diabetes self-management (The FUSED model): a systematic review and meta-ethnography of the barriers, facilitators and recommendations for sustaining self-management skills after attending a structured education programme. BMC Health Serv Res. 2018;18:898.

10. Bhatia V, Bhatia E. Diabetes in Children And Young Adults, 2019. Available at: https://www.ispae.org.in/download_docs/ Diabetes_in_children_and_young_adults_for_website.pdf. Accessed 28 April, 2020.

11. International Diabetes Federation. IDF Diabetes Atlas, Ninth edition, 2019. Available at: https://www.diabetesatlas.org/en/ . Accessed 29 April, 2020.

Publisher's Note Springer Nature remains neutral with regard to jurisdictional claims in published maps and institutional affiliations. 